Research Article

\title{
Study of Gob-Side Entry Retaining Technology with Roof Cutting under Upper Roadway Condition
}

\author{
Xingen Ma $\mathbb{D}^{1,},{ }^{1,2,3}$ Manchao He, ${ }^{3}$ Xuewei Sun, ${ }^{4}$ Jianfeng Li, ${ }^{1}$ Gang He, ${ }^{1}$ and Enze Zhen ${ }^{5}$ \\ ${ }^{1}$ Coal Burst Research Center of China, Jiangsu, Xuzhou 221000, China \\ ${ }^{2}$ Huaneng Coal Technology Research Co., China, Huaneng, Beijing 100070, China \\ ${ }^{3}$ State Key Laboratory for Geomechanics and Deep Underground Engineering, \\ China University of Mining and Technology (Beijing), Beijing 100083, China \\ ${ }^{4}$ Yixin Coal Mine, Longmei Group, Hegang 154100, China \\ ${ }^{5}$ School of Architecture and Civil Engineering, Huangshan University, Huangshan 245041, China
}

Correspondence should be addressed to Xingen Ma; 294185559@qq.com and Enze Zhen; zhenenze0@163.com

Received 24 July 2021; Accepted 12 October 2021; Published 17 November 2021

Academic Editor: Vadim V. Silberschmidt

Copyright (c) 2021 Xingen Ma et al. This is an open access article distributed under the Creative Commons Attribution License, which permits unrestricted use, distribution, and reproduction in any medium, provided the original work is properly cited.

Gob-side entry retaining technology with roof cutting (GERRC) has been widely used in flat and near-flat coal seam conditions, but its application under inclined coal seam is still very deficient. In order to further improve the application system of GERRC and overcome the application difficulties under special geological conditions, this paper takes the 43073 working face of Yixin coal mine as an example to research the GERRC with upper roadway under gently inclined thick coal seam. Firstly, the difficulties in the upper entry retaining with inclined coal seam are analyzed and the corresponding key technologies and system designs are put forward. Subsequently, the roof cutting and upper entry retaining are designed in detail according to geological conditions of test working face, and the roof cutting and pressure releasing effect is analyzed by numerical simulation to expound the stress distribution and pressure releasing mechanism of surrounding rock. Finally, the upper entry retaining field test is carried out to verify the feasibility and applicability of the technology and related designs. Through field monitoring, it is found that the weighting step increases significantly, the weighting strength decreases effectively on the roof cutting side, and the pressure relief effect is obvious. Meanwhile, the maximum roof to floor convergence is $361 \mathrm{~mm}$ and the maximum shrinkage of both sides is $280 \mathrm{~mm}$, so the retained entry can meet the reuse requirement of adjacent working face.

\section{Introduction}

In the gob-side entry retaining technology of longwall mining, only one entry needs to be excavated during one working face mining and another entry is obtained by retaining during the adjacent working face mining. So the technology has the advantages of saving section coal pillars, reducing the amount of entry excavation, and prolonging the mine service life $[1,2]$. Under the current increasingly tense situation of coal resources, this mining technology has high research and popularization value, and related scholars have also carried out a lot of research work [3, 4]. For example, Zhu Haotian takes the 9307 working face of Yangmei group as an example and successfully carries out gob-side entry retaining test by pier-column method, and the deformation of pier-column is controlled within $150 \mathrm{~mm}$ [5]. Zhang Sheng takes the 9301 working face of Tangkou coal mine as an example, using coal gangue, fly ash, and cement as filling materials, and successfully carries out gob-side entry retaining test by solid filling method [6]. Li Youcun takes the 21001 working face of Wangcun coal mine as an example and successfully carries out the gob-side entry retaining test in fully mechanized caving face by adopting entry roof reinforcement support measures using wooden stack, gangue bag high prestressing anchor cable, and so on [7].

The above achievements have greatly enriched the research idea and practical experience of gob-side entry 
retaining technology in China, but there are still many restrictive factors hindering its wide application. First, the price of filling materials is usually high and the filling efficiency is limited. Second, the backfilling process of goaf is often complex, which has great influences on the mining and succession of working faces $[8,9]$. In order to seek a more efficient and economical way of entry retaining, Professor $\mathrm{He}$ Manchao puts forward the gob-side entry retaining technology with roof cutting (GERRC) based on the theory of short arm beam on the basis of the existing research in 2008 [10].

After the development in recent years, the GERRC has been successfully tested and popularized in many mines. Sun Xiaoming takes the 1610 working face of Nantun coal mine as an example and studies the design method of key parameters for gob-side entry retaining by roof cutting pressure releasing under the condition of thin coal seam [11]. Zhang Guofeng takes the 2422 working face of Baijiao coal mine as an example and elaborates the implementation process and matching monitoring method of the roof cutting pressure releasing gob-side entry retaining technology [12]. Guo Zhibiao takes the 3118 working face of Jiayang coal mine as an example and analyzes the stress field evolution of surrounding rock with roof cutting pressure releasing by numerical simulation $[13,14]$. It can be seen that this technology is mainly used on near-flat thin or medium-thick coal seam in the existing research, but the application in thick coal seam or inclined coal seam is still insufficient because of the influences of rock pressure, entry support, goaf filling effect, and other factors. Therefore, in order to further improve the application system of this technology and overcome the application difficulties under special geological conditions, this study takes the 43073 working face of Yixin coal mine as an example to carry out the adaptability study of GERRC with upper roadway under gently inclined thick coal seam condition.

\section{Research Background}

2.1. Technical Characteristics. The GERRC can realize automatic roadway formation without coal pillars by roof cutting along the entry. The technology has been successfully tested in many mines under the condition of near-flat coal seam (as shown in Figure 1(a)). However, there are still many limitations in the application of this technology under the condition of inclined coal seam. The GERRC under the condition of inclined coal seam can be divided into two types, that is, upper and lower entry retaining as shown in Figure 1(b) and 1(c) [15].

Among them, the difficulty of lower entry retaining is that when the goaf roof caves, the caving gangue will gather along the inclination angle of the coal seam to the lower entry direction, which will cause a greater impact on the gangue retaining support. While the difficulty of upper entry retaining is that the gangue caving from goaf roof will accumulate away from the upper entry direction, the gangue wall of retained entry cannot be formed well to support the overlying strata. The main solutions of lower entry retaining are to increase the strength of gangue retaining support and reduce the height of roof cutting properly, which has been successfully tested in Fucheng coal mine. However, the upper entry retaining is more difficult. The key parameters such as the roof cutting height and angle should be adjusted accordingly and the supporting design should also be improved appropriately. So taking the 43073 working face of Yixin coal mine of Longmei group as an example, this paper carries out the first test of roof cutting pressure releasing bob-side entry retaining technology with upper roadway under gently inclined thick coal seam condition.

2.2. Project Overview. The 43073 working face of Yixin coal mine Longmei group is located in the third mining level of Hegang coalfield. The strike length of the working face is $400 \mathrm{~m}$, the inclination length is $170 \mathrm{~m}$, and the layout plan is shown in Figure 2(a). The basic parameters of the 43073 working face are shown in Table 1, the roof lithology column diagram is shown in Figure 2(b), and the related parameters of each stratum are shown in Table 2.

Comprehensive mechanized mining method is adopted in the test face. The test entry is the auxiliary roadway of the 43073 working face, and the retaining section is $380 \mathrm{~m}$ long in front of open-off cut. The adjacent working face intends to use this retained entry section for reverse direction mining. The reverse mining of adjacent working faces has no impact on the entry retaining procedure, but after the entry retaining is completed, the mining of adjacent working face needs to wait until the retained entry is stable, so as to avoid the entry damage caused by mining impact.

\section{Design of Key Technical Parameters}

The biggest difference of entry retaining in inclined working face lies in the lateral accumulation of gangue in goaf; that is, gangue will accumulate to the side close to or away from the roadway due to the existence of dip angle. Therefore, the key of entry retaining in inclined working face lies in retaining roadway gangue support and roof cutting height, which will directly affect the effect of entry retaining. When entry retaining with the upper roadway, the gangue retaining support is weakened and the roof cutting height is increased; when entry retaining with the lower roadway, the gangue retaining support is strengthened and the roof cutting height is reduced.

3.1. Roof Cutting Design. Roof cutting design directly affects the success and effect of entry retaining in the new technology. The reasonable roof cutting parameter design should meet the filling demand of goaf on the entry retaining side as far as possible under the condition of saving the roof cutting workload. Under normal near-flat coal seam condition, the roof cutting height can be calculated according to the bulking coefficient of goaf roof rocks as[16]

$$
H_{F}=\frac{\left(H_{M}-\Delta H_{1}-\Delta H_{2}\right)}{(K-1)}
$$

where $H_{F}$ is the roof cutting height, $\mathrm{m} ; H_{M}$ is the coal seam thickness, $\mathrm{m} ; \Delta H_{1}$ is the amount of roof subsidence, $\mathrm{m} ; \Delta H_{2}$ 


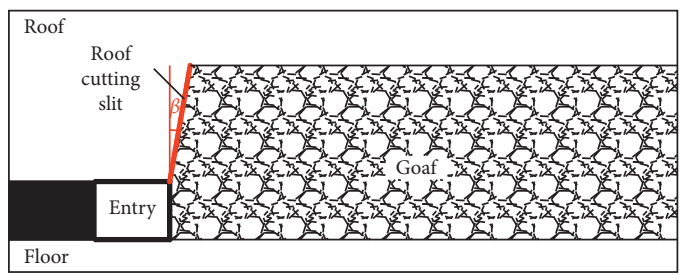

(a)

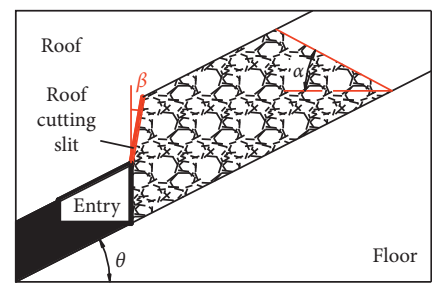

(b)

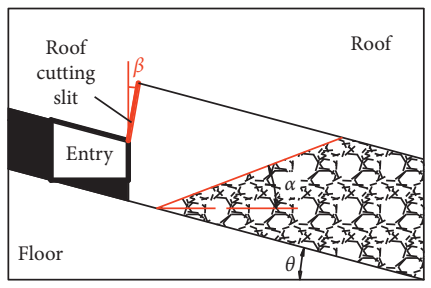

(c)

FIGURE 1: Classification of roof cutting pressure releasing gob-side entry retaining. (a) Entry retaining with near-flat coal seam. (b) Lower entry retaining. (c) Upper entry retaining.

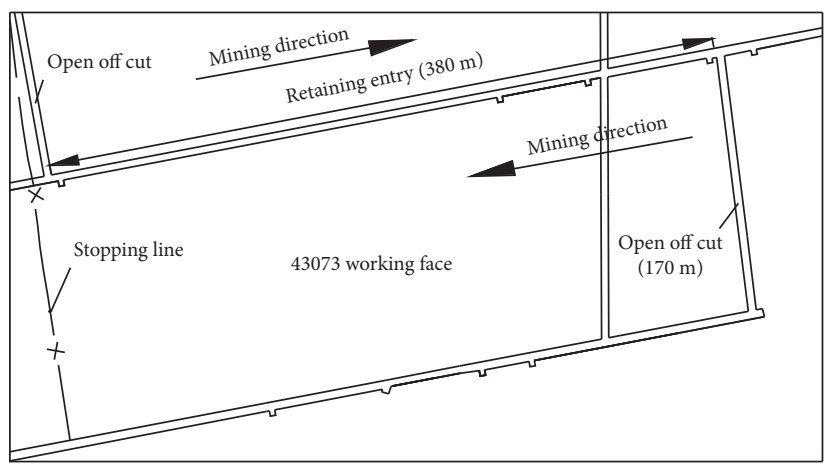

(a)

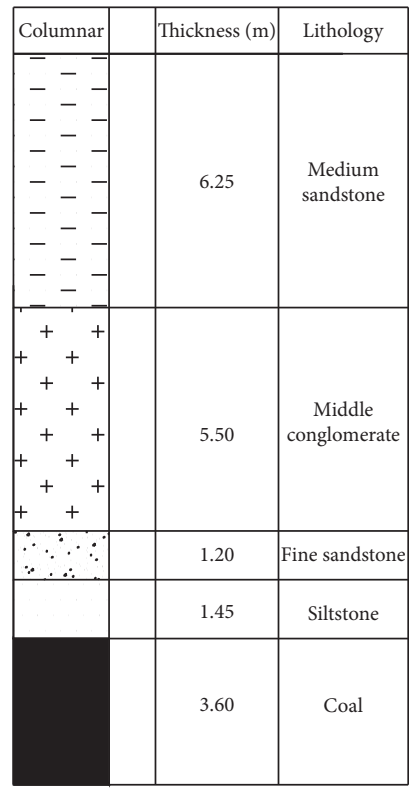

(b)

FIgURE 2: Layout and roof lithology of the 43073 working face. (a) Layout of the working face. (b) Lithological profile.

is the amount of floor heave, $\mathrm{m}$; $K$ is the bulking coefficient of roof.

According to the roof condition of the 43073 working face, the bulking coefficient of roof is taken as 1.4 in this study [16]. Without considering the roof subsidence and floor heave, the roof cutting height is designed as $9.0 \mathrm{~m}$ according to the mining height and above equation. Under the upper entry retaining process with inclined coal seam, the gangue collapsing from the goaf roof will slide away from the entry retaining side, so the roof cutting height should be increased appropriately. However, from the roof lithology column of the working face, it can be seen that there is a thick stable medium sandstone rock layer above the coal seam $8.15 \mathrm{~m}$. If increasing the roof cutting height with $1-2 \mathrm{~m}$, not only is the roof cutting workload greatly increased, but also the medium sandstone strata in the roof cutting height increasing range is still difficult to collapse, which has little significance for the filling of goaf on the entry retaining side. Therefore, the ultimate design of roof cutting height is maintained at $9.0 \mathrm{~m}$, and the goaf filling is mainly relying on the strata within lower $8.15 \mathrm{~m}$ range of roof.

Another key parameter of roof cutting design is the cutting angle. As shown in Figure 1, the design of roof cutting angle under normal conditions should mainly consider two aspects: one is to minimize the friction effect of goaf roof caving on the roof of retained entry; another is to 
TABLE 1: Basic parameters of the 43073 working face.

Coal seam thickness $(\mathrm{m})$

Mining height $(\mathrm{m})$

Strike length $(\mathrm{m})$

Immediate roof/thickness $(\mathrm{m})$

Main roof/thickness (m)

Depth (m)

Dig angle/average dip angle $\left({ }^{\circ}\right)$

Inclination length $(\mathrm{m})$

Immediate floor/thickness (m)

Main floor/thickness (m)

\section{6}

3.6

400

Siltstone $/ 1.45$

Middle conglomerate/5.50

440-574

$16 \sim 20 / 18$

170

Fine sandstone/ 6.00

Coarse sandstone/19.30

TABle 2: Parameters of the rock layers.

\begin{tabular}{|c|c|c|c|c|c|c|}
\hline Lithology & $\begin{array}{c}\text { Density (kN/ } \\
\left.\mathrm{m}^{3}\right)\end{array}$ & $\begin{array}{c}\text { Tensile strength } \\
(\mathrm{MPa})\end{array}$ & $\begin{array}{l}\text { Internal friction } \\
\text { angle }\left(^{\circ}\right)\end{array}$ & $\begin{array}{c}\text { Cohesion } \\
(\mathrm{MPa})\end{array}$ & $\begin{array}{l}\text { Bulk modulus } \\
\qquad(\mathrm{GPa})\end{array}$ & $\begin{array}{c}\text { Shear modulus } \\
(\mathrm{GPa})\end{array}$ \\
\hline Fine sandstone & 23 & 7.3 & 28 & 1.0 & 3.81 & 3.05 \\
\hline Medium sandstone & 24 & 8.4 & 32 & 2.6 & 11.49 & 7.26 \\
\hline Siltstone & 22 & 4.3 & 28 & 0.8 & 2.11 & 1.86 \\
\hline $\begin{array}{l}\text { Middle } \\
\text { conglomerate }\end{array}$ & 26 & 10.2 & 35 & 3.3 & 14.16 & 9.21 \\
\hline Coal & 13 & 3.3 & 29 & 0.2 & 0.35 & 0.18 \\
\hline Coarse sandstone & 25 & 9.6 & 33 & 2.9 & 13.21 & 8.75 \\
\hline
\end{tabular}

minimize the damage of roof cutting blasting to the original roof bolt cable support [15]. Under the condition of upper entry retaining, the gangue collapsing from the goaf roof will accumulate far away from the retained upper entry, so the friction on the roof cutting surface is usually small and the roof cutting angle can only be designed from the protection of bolt cable support. To sum up, according to the previous test experience, the roof cutting angle is designed as $10^{\circ}$ in the roof cutting design of the 43073 working face. At the same time, the smaller roof cutting angle can also cut off the larger volume of goaf roof, which can make up for the shortcoming of goaf insufficient filling on the upper entry retaining side to a certain extent.

3.2. Blasting Design. In the upper entry retaining process with gently inclined coal seam, the roof cutting still needs to be realized by bidirectional shaped charge tension blasting technology, and the technical equipment and principle are shown in Figure 3 [17]. The size of single shaped charge tube is $\varphi 36.5 \mathrm{~mm} \times 1500 \mathrm{~mm}$, and some tubes can be connected and installed by connecting sleeves according to the requirement of blasting depth. There is a row of holes on each side of the tube, and the locked groove at two ends can ensure that the tube always faces a certain direction when connecting and installing. When cutting the roof, a certain amount of explosive rolls are loaded into the shaped charge tubes, then putting them into the blasting hole in the roof and sealing the holes. The blasting energy of the explosive can be directionally transmitted along the shaped charge direction, effective tension force can be formed in the direction of nonshaped energy, and the directional tension presplitting can be formed making use of the poor tensile capacity of rock mass.
The charge quantity and structure of the explosive roll in the shaped charge tube, the blasting hole spacing, and the amount of blasting hole at single initiation should all be determined by field test. The blasting test examines the blasting effect, but there are no special requirements for explosives. The test procedure is shown in Figure $4[18,19]$. Firstly, a single-hole blasting test is carried out to determine the reasonable charge of a single hole, and the reasonable charge should be able to form effective cracks in the blasting hole without collapse. Secondly, an interval-hole blasting test is carried out to determine the reasonable hole spacing, usually including $300 \mathrm{~mm}, 400 \mathrm{~mm}, 500 \mathrm{~mm}$, and $600 \mathrm{~mm}$ four types. In this step, the peephole between each two blasting holes should be checked to observe the penetration of the cracks in the hole. Finally, a continuous-hole blasting test is carried out to determine the amount of blasting hole at single initiation, and the main index is harmful gas concentration at this step.

Through the single-hole blasting test in the 43073 working face, the charge structure of the blasting hole is designed as 43210 and the sealing length is designed as $2 \mathrm{~m}$. That is, each blasting hole is filled with five shaped charge tubes, the bottom tube is cut to be $1 \mathrm{~m}$ long, and from top to bottom of blasting hole, each tube is charged $4,3,2,1$, and 0 rolls of explosive, respectively. The statistical analysis of crack rate per meter in peephole of interval-hole blasting test is shown in Figure 5. It can be seen that hole collapse occurs in $5-6 \mathrm{~m}$ section of peephole under $300 \mathrm{~mm}$ spacing condition, and the average crack rates under $400 \mathrm{~mm}, 500 \mathrm{~mm}$, and $600 \mathrm{~mm}$ spacing conditions are $87 \%, 82 \%$, and $74 \%$, respectively. In order to reduce the workload of roof cutting blasting and ensure the effect, the blasting spacing is ultimately selected as $400 \mathrm{~m}$. Combining with the requirements of mining speed and upper limit of harmful gas concentration in entry, the amount of blasting hole at single 


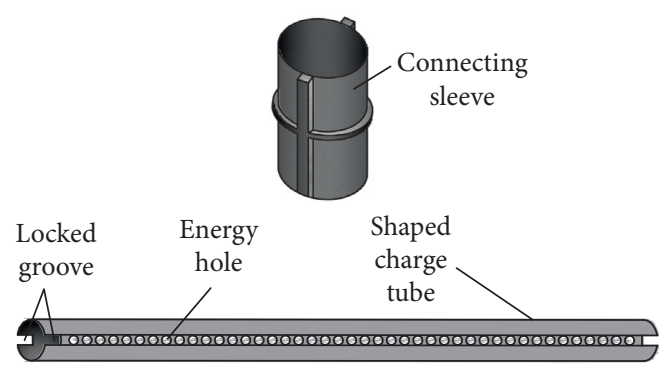

(a)

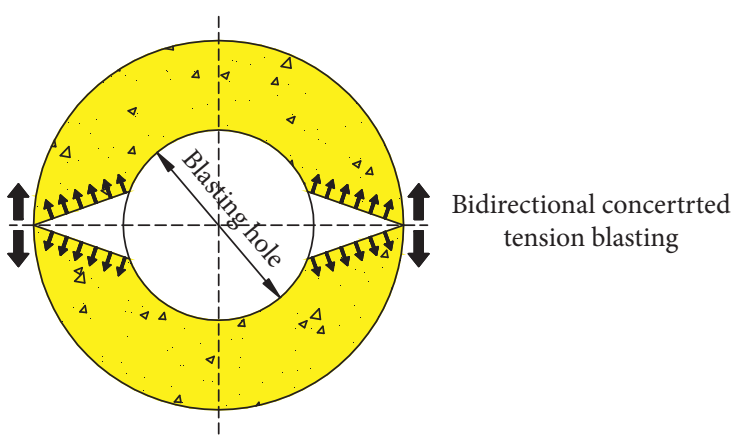

(b)

FIGURE 3: Devices and principle of bilateral bidirectional shaped charge tension blasting technology. (a) Connecting sleeve and shaped charge tube. (b) Blasting principle.

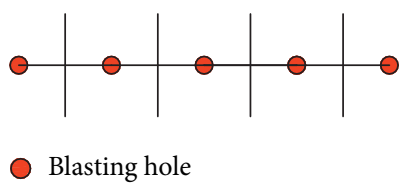

(a)

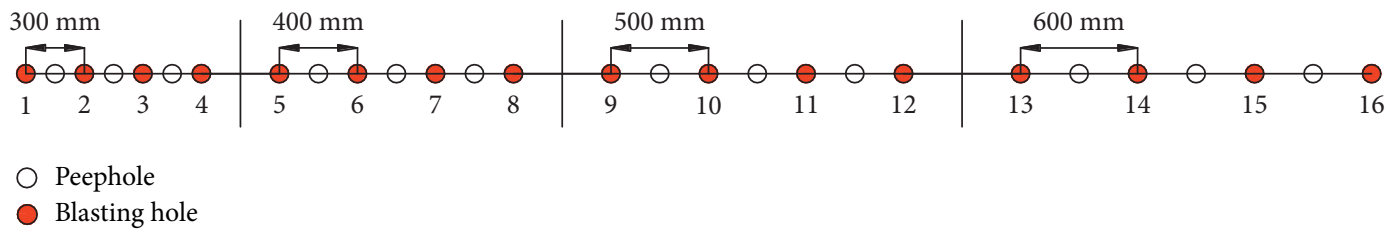

(b)

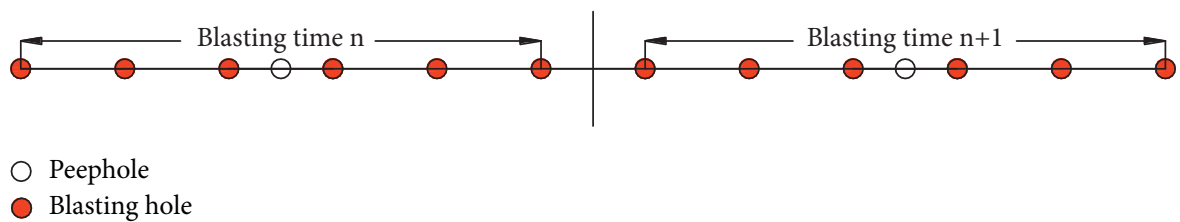

(c)

Figure 4: Holes layout in blasting test. (a) Single-hole blasting test. (b) Interval-hole blasting test. (c) Continuous-hole blasting test.

initiation is determined to be 6 holes. The common presplitting effect in peephole is shown in Figure 6.

3.3. Design of Reinforcement Support. In the GERRC, the entry roof needs to undergo several disturbances, such as tunneling, mining, entry retaining, and secondary mining. The deformation of the roof is usually large, and the conventional anchor cable support cannot effectively meet the needs of the field support demand under dynamic pressure and large deformation conditions. Therefore, the entry reinforcement support of entry retaining test in the 43073 working face uses the constant resistance large deformation anchor cable $[20,21]$.

The structure of constant resistance large deformation anchor cable is shown in Figure 7, whose supporting principle is shown in Figure 8 and constitutive relation and energy model are shown in Figure 9 [22]. When the tension of cable is greater than the constant resistance value, the anchor cable lock head can be retracted into the constant resistance device to provide a certain amount of constant resistance deformation for the anchor cable. The anchor cable can be regarded as an ideal model of elastic and plastic components. When the pull force is less than the constant resistance of anchor cable, the anchor cable is in the elastic stage: $P=K_{g x}$, where $P$ is the anchor cable load, $K_{g}$ is the stiffness coefficient, and $x$ is the amount of elastic extension. When the pull force increases to the constant resistance value, the anchor lock exhibits plastic slip, then $P=P_{0}$, where $P_{0}$ is the constant resistance value. Therefore, when the plastic slip occurs, the energy absorbed by the constant resistance anchor cable is

$$
W=\frac{P_{0} x_{0}}{2+P_{0}\left(x^{\prime}-x_{0}\right)}
$$

where $x_{0}$ is the maximum amount of elastic deformation and $x$ ' is the total deformation amount. 


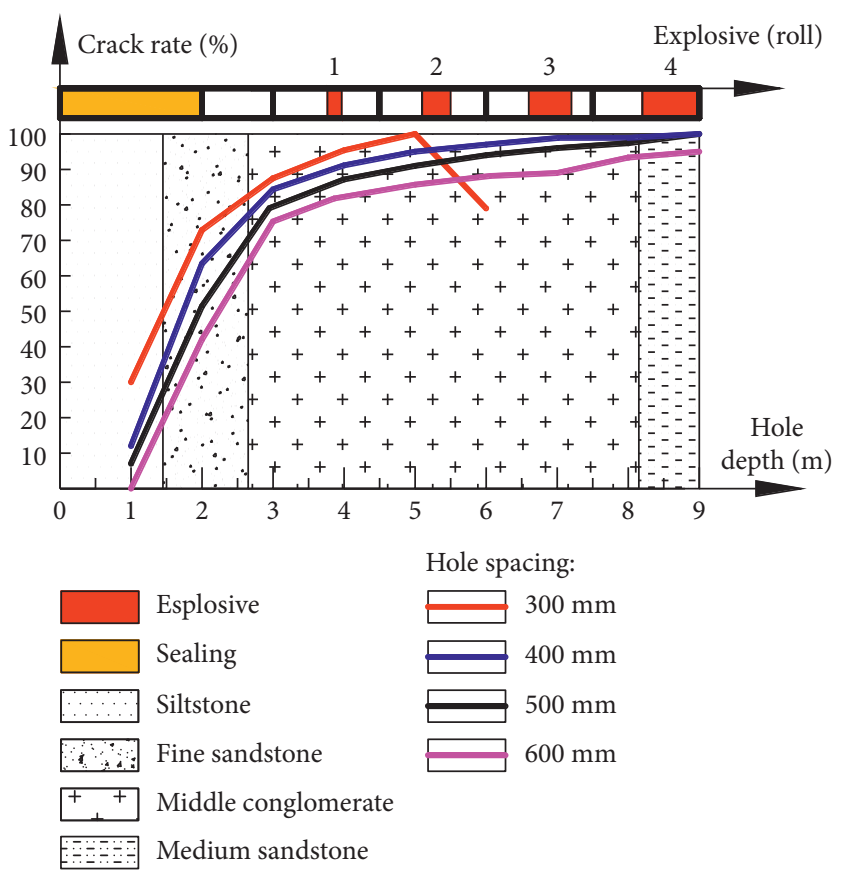

FIGURE 5: Result of interval-hole blasting test.

The main reinforcement support area of the retained entry roof is also the roof cutting range, so the length of the anchor cable should be 1-2 m longer than the height of roof cutting. That is, the length of the anchor cable used in the 430743 working face is $11 \mathrm{~m}$ long. According to the theory of suspension, the support strength of anchorage cable can be calculated according to the following formula [7]:

$$
P \geq H_{F} \rho_{d}\left(1+\frac{H_{F} \tan \beta}{2 L_{h}}\right),
$$

where $P$ is the pull force of anchor cable; $L_{h}$ is the width of entry; $\rho_{d}$ is the roof density in the roof cutting range. When there are several layers in the roof cutting range, then

$$
\rho_{d}=\sum_{i=1}^{n} \rho_{i} \frac{D_{i}}{H_{F}},
$$

where $n$ is the number of rock layers; $\rho_{i}$ is single layer density; $D_{i}$ is single layer thickness. According to the roof lithology of the 43073 working face, it is calculated that $\rho_{d}=24.8 \mathrm{KN} / \mathrm{m}^{3}$ and $P<261.7 \mathrm{KN} / \mathrm{m}^{2}$. As the design, the constant resistance value of this anchor cable used in coal mine is $350 \mathrm{KN}$; that is, the support density of this anchor cable is $0.75 / \mathrm{m}^{2}$ at least. Therefore, there are designed three anchor cables on each row and the row spacing is $0.8 \mathrm{~m}$ in the upper entry reinforcement support of the 43073 working face. As shown in Figure 10, the roof cutting side of entry suffers strong disturbances of blasting and roof caving, so the anchor cables on this side are all adopted constant resistance large deformation anchor cable; the row of anchor cables on the middle of entry roof is alternately arranged with common steel anchor cable and constant resistance anchor cable; the coal wall side of entry suffers little disturbances of blasting and roof caving, so the anchor cables on this side are all adopted steel anchor cable.

3.4. Design of Gangue Retaining Support. Gangue retaining support is the special link of GERRC, and the effective gangue retaining support should be carried out in time behind the working face to prevent gangue from rushing into the retained entry when the goaf roof caving [23-25]. At present, the commonly used method of gangue retaining support is U-shaped steel + metal mesh support. In terms of the pressure of gangue retaining support, the pressure is the highest under the low entry retaining with inclined coal seam, the pressure is middle under the near-flat coal seam, and the pressure is the lowest under the upper entry retaining with inclined coal seam. The U-shaped steel type used for gangue retaining support is usually $36 \mathrm{U}$, and the support spacing of it is usually $500 \mathrm{~mm}$ in gangue retaining support under near-flat coal seam. Under lower entry retaining, the support spacing should be reduced appropriately according to the mining height and coal seam dip angle, and under upper entry retaining, the support spacing can be increased appropriately to save material consumption.

As shown in Figure 11(a), the U-shaped steel support spacing of the 43073 working face in Yixin coal mine is designed as $600 \mathrm{~mm}$. In order to determine whether the spacing is reasonable, a pressure sensor is installed between the U-shaped steel and gangue wall to measure the gangue retaining support pressure as shown in Figure 11(b). The measuring result is shown in Figure 12(a), and the field effect of gangue retaining support is shown in Figure 12(b). It can be seen that the pressure of gangue retaining begins to appear at $20 \mathrm{~m}$ behind the working face and reaches a peak value of $0.28 \mathrm{MPa}$ when it is $73 \mathrm{~m}$ behind. Then the pressure of gangue retaining gradually stabilizes after $160 \mathrm{~m}$ behind the working face; that is, the gangue wall is effectively formed gradually. As the field effect shows, the crushed gangue wall is denser, and U-shaped steels do not appear obvious compression deformation, so the design of gangue retaining support is reasonable and the formed gangue wall can support overburden effectively.

3.5. Temporary Support Design. In the GERRC, the temporary support includes two parts: the advance temporary support and the lagging temporary support. Among them, the purpose of advance temporary support is to prevent the disturbance and destruction to the entry caused by the stress concentration in front of the working face. The advance temporary support of the 43073 working face follows the support mode of adjacent working face using leaving coal pillars mining method. As shown in Figure13(a), the DW40$300 / 110 x$ single prop is selected for support, the support row spacing is $1 \mathrm{~m}$, each row contains three props, and the support range is $0-30 \mathrm{~m}$ in advance of working face.

The lagging temporary support is also a special link of GERRC. The key area of lagging temporary support is the dynamic pressure area, so the parameters of this temporary support can be calculated according to the 


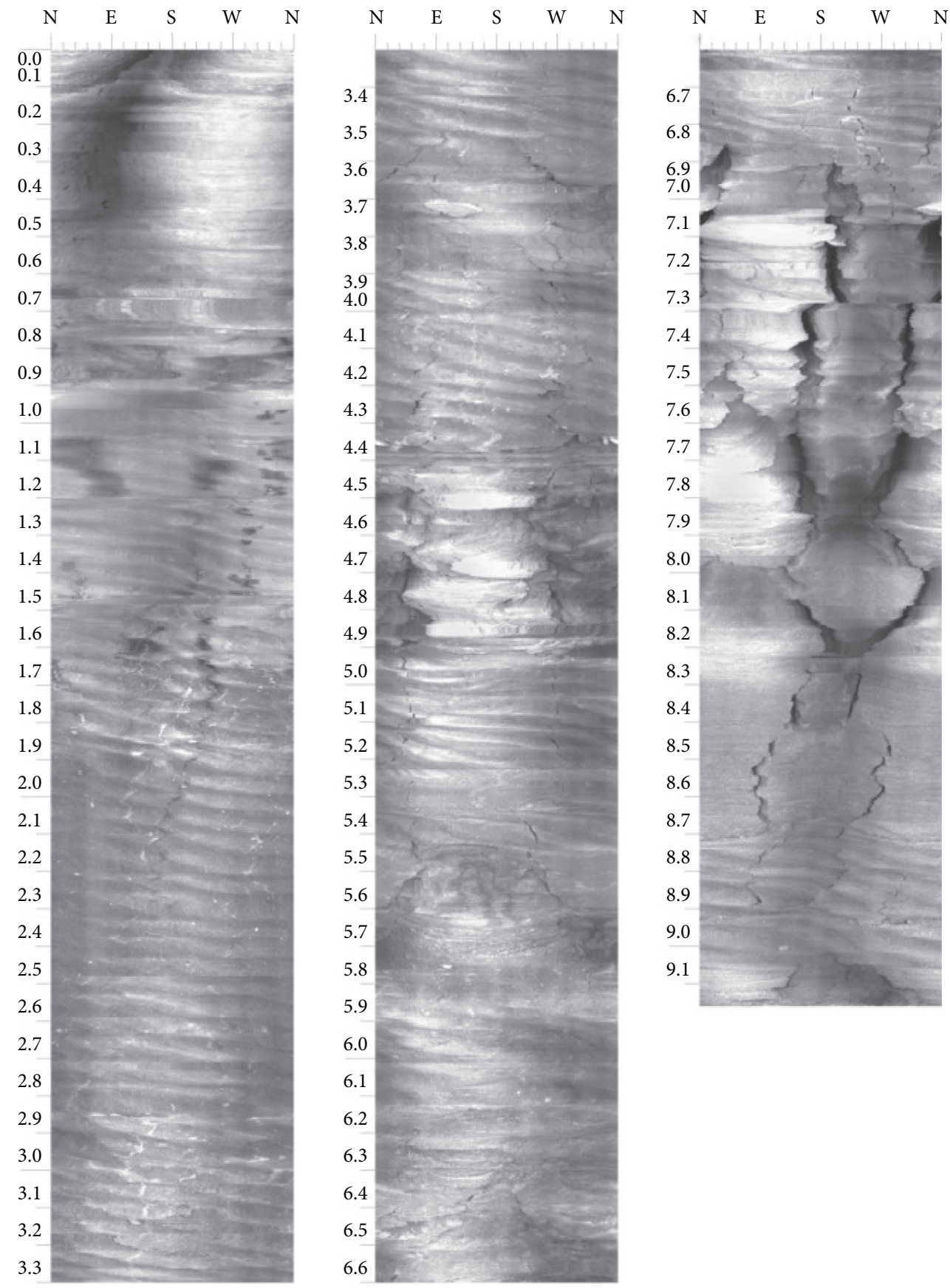

FIgURE 6: Common presplitting effect in peephole.

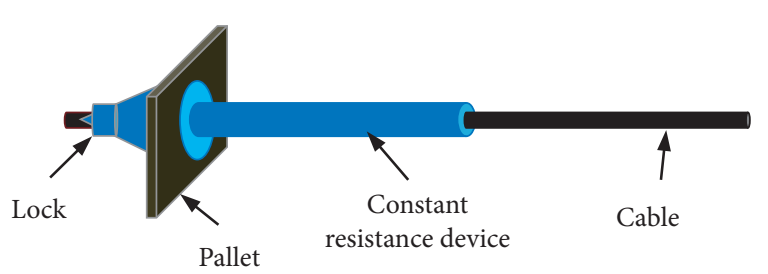

Figure 7: Structure of constant resistance large deformation anchor cable. surrounding rock structure of the dynamic pressure area. As shown in Figure 14, two sides of the retained entry in the dynamic pressure area are supported by the coal wall and the gangue wall, respectively, and the gangue wall is not stable yet. Among them, $T_{A}$ is the horizontal thrust of block $\mathrm{A} ; N_{A}$ is the shear force of block $\mathrm{A} ; M_{A}$ is the bending moment of block $\mathrm{A}$ at point $\mathrm{A}^{\prime} ; T_{B}, N_{B}$, and $M_{B}$ have the corresponding meanings as $T_{A}, N_{A}$, and $M_{A}$, respectively, but for block $\mathrm{B}$; $M_{0}$ is the immediate roof 


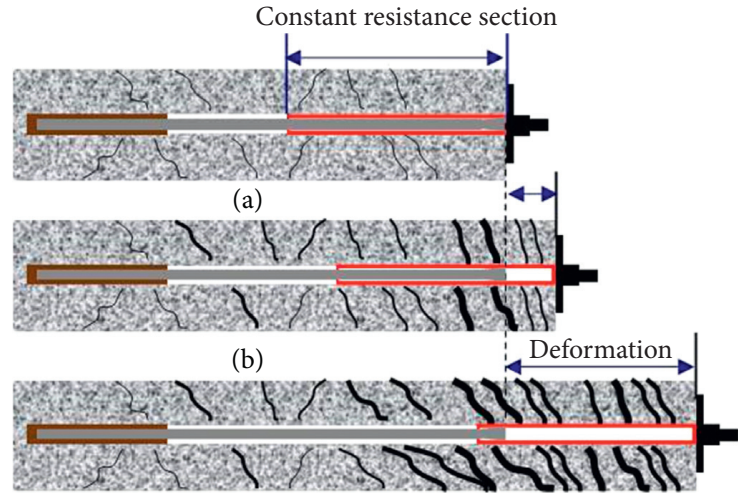

(c)

Figure 8: Principle of the anchor cable. (a) Before deformation. (b) Under deformation. (c) After deformation.

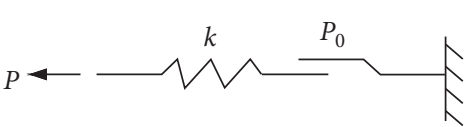

(a)

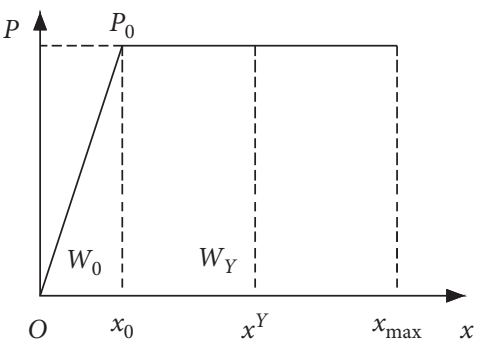

(b)

FIGURE 9: Constitutive and energy model of the anchor cable. (a) Constitutive relation. (b) Energy model.

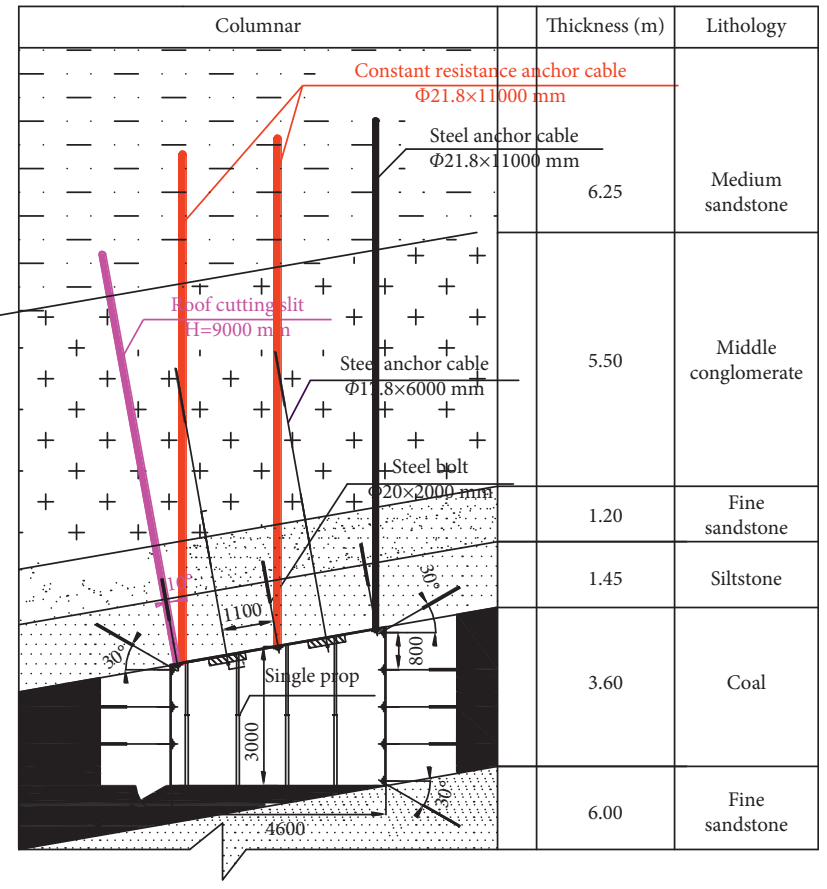

Figure 10: Design of roof cutting and entry supporting in the 43073 working face. limit bending moment; $x_{S}$ is the lateral width of the limit equilibrium zone in the coal wall; $\sigma$ is the coal wall plastic zone support; and $F_{2}$ is the gangue wall support. In this area, the gangue wall is not stable, so $F_{2}$ is small. Particularly in a certain area close to the working face, $F_{2}$ is approximately 0 . When calculating the entry support force $F_{1}$, the rotary deformation at the elastic-plastic boundary $\mathrm{A}^{\prime}$ of block A should be considered first, and the width of the limit equilibrium zone in the coal wall and the support force of the plastic zone to roof are $[26,27]$

$$
\begin{aligned}
x_{s} & =\frac{H_{M} k_{a}}{x} \ln \left(\frac{k \gamma H+c^{\prime} / \tan \varphi^{\prime}}{c^{\prime} / \tan \varphi^{\prime}+p_{x} / k_{a}}\right), \\
\sigma & =\left(c^{\prime} / \tan \varphi^{\prime}+p_{x} / k_{a}\right) e^{2 x \tan \varphi^{\prime} / m k_{a}}-\frac{c^{\prime}}{\tan \varphi^{\prime}},
\end{aligned}
$$

where $c^{\prime}$ and $\varphi^{\prime}$ are the cohesive force and internal friction angle, respectively, of the interface between the coal seam and the roof; $k_{a}$ is the lateral pressure coefficient; $k$ is the maximum stress concentration coefficient; $H$ is the mining depth; and $p_{x}$ is the coal wall support strength. The stress states of blocks A and B are analyzed by the static equilibrium method [26]: 


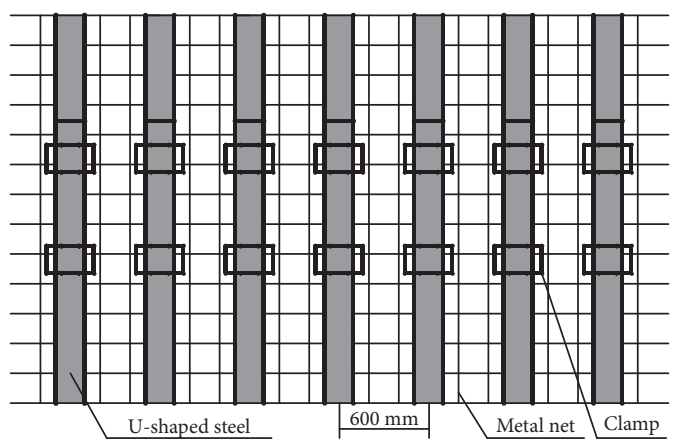

(a)

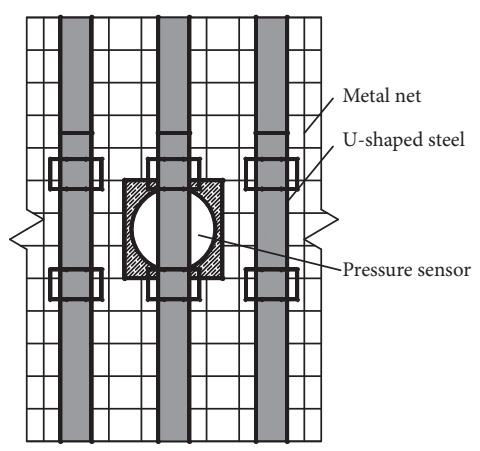

(b)

FIGURE 11: Design of gangue retaining support. (a) Support design with U-shaped steel. (b) Pressure monitoring of gangue retaining support.

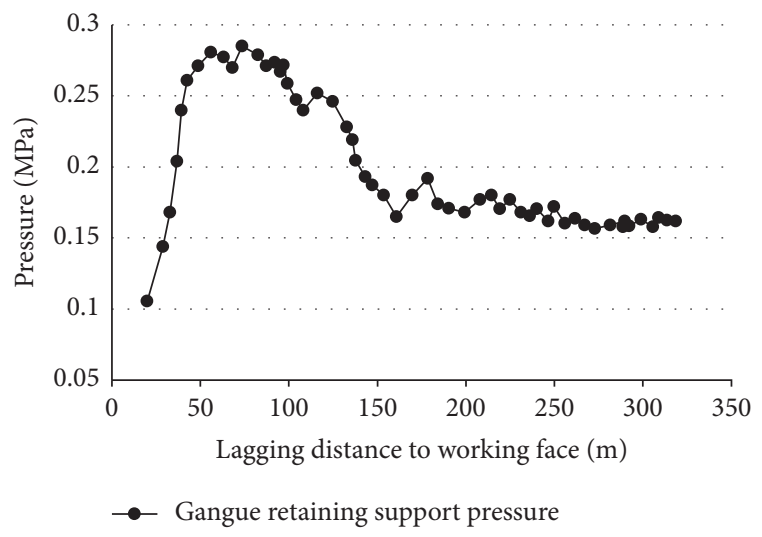

(a)

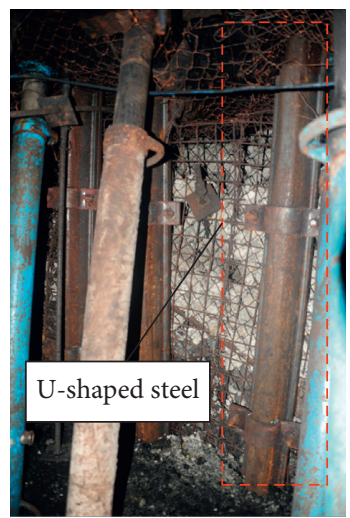

(b)

Figure 12: Monitoring results of gangue retaining support. (a) Gangue retaining support pressure. (b) Field effect of gangue retaining support.

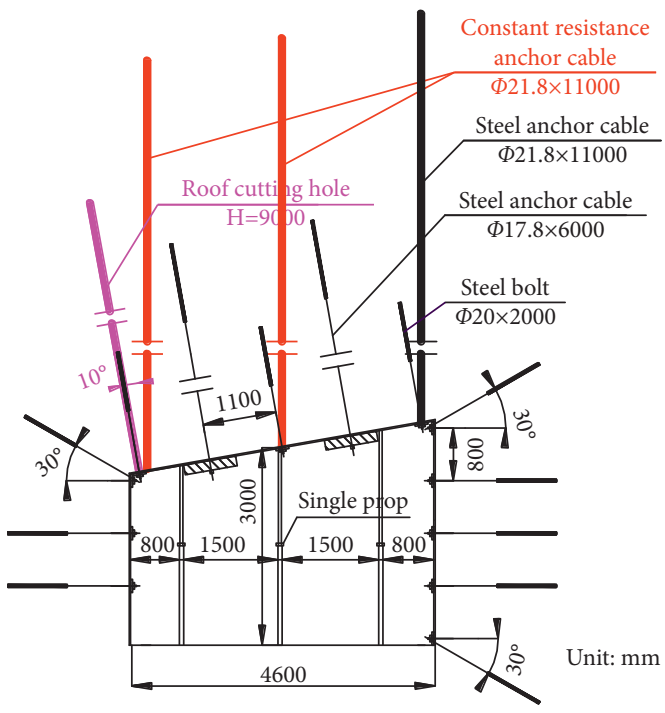

(a)

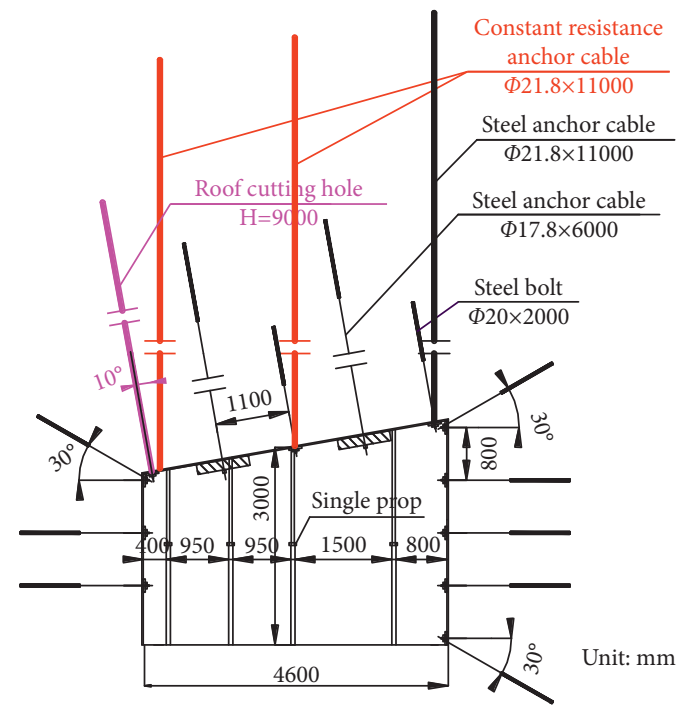

(b)

FIGURE 13: Advance and lagging temporary support design of the 43073 working face. (a) Advance temporary support. (b) Lagging temporary support. 


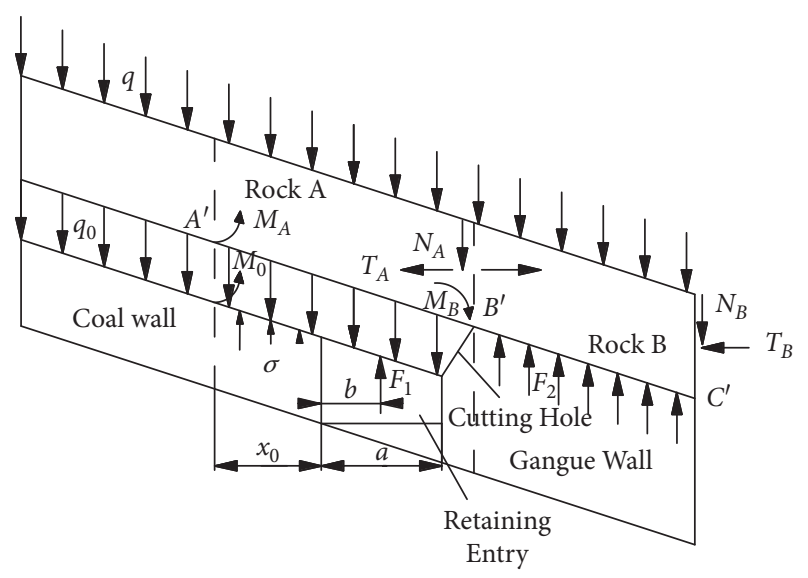

FIGURE 14: Simplified mechanical model of dynamic pressure area.

$$
\begin{gathered}
\text { Block } \quad\left\{\begin{array}{l}
\sum F_{X}=0 \\
\sum F_{y}=0 \\
\sum M_{B}=0
\end{array}, \quad\right. \text { then } \\
\left\{\begin{array}{l}
T_{A}=T_{B} \\
N_{A}=N_{B}+q L \\
M_{B}+T_{B}\left(H-\Delta S_{C}\right)-N_{B} L-q L^{2} / 2=0
\end{array},\right. \text { then }
\end{gathered}
$$

$$
\begin{aligned}
& N_{B}=\frac{M_{B}+T_{A}\left(H-\Delta S_{B}\right)-q L^{2} / 2}{L}, \\
& N_{A}=\frac{M_{B}+T_{A}\left(H-\Delta S_{B}\right)-q L^{2} / 2}{L} .
\end{aligned}
$$

Rock A: $\sum M_{A}=0$, then

$$
\begin{gathered}
M_{A}+M_{0}+F_{1}\left(x_{s}+b\right)+\int_{0}^{x_{s}} \sigma\left(x_{s}-x\right) \mathrm{d} x+T_{A}\left(H-\Delta S_{A}\right) \\
-\frac{M_{B}-q L^{2} / 2-q_{0}\left(x_{s}+L_{h}\right)^{2}}{2-N_{A}\left(x_{s}+L_{h}\right)=0}, \\
T_{A}=T_{B}=\frac{q L}{2\left(H-\Delta S_{B}\right)},
\end{gathered}
$$

where $L$ is the lateral breaking span of the basic roof; $\triangle S_{A}$ is the subsidence of rock $\mathrm{A}$ at point B'; and $\triangle S_{B}$ is the subsidence of rock $\mathrm{B}$ at point $\mathrm{C}^{\prime} . F_{1}$ is determined as follows:

$$
F_{1}=\left[\frac{M_{B}\left(L+x_{s}+L_{h}\right)+q\left(x_{s}+L_{h}\right)^{2} / 2+q L\left(x_{s}+L_{h}\right) / 2+q_{0}\left(x_{s}+L_{h}\right)^{2} / 2+q\left(x_{s}+L_{h}\right)}{2-M_{A}-M_{0}-q L / 4-\int_{0}^{x_{s}} \sigma\left(x_{s}-x\right) \mathrm{d} x /\left(x_{s}+b\right)}\right] .
$$

Taking c'=0.1 MPa, $\varphi^{\prime}=18^{\circ}, K_{a}=2, L=15 \mathrm{~m}, \gamma=13$, $25 \mathrm{KN} / \mathrm{m}^{3}$, and $p_{x}=0.03,0.04 \mathrm{MPa}$ into the above calculation, the entry roof supporting demand of per meter is $1430 \mathrm{KN}$. The working resistance of the selected single prop is $300 \mathrm{kN}$, so its support density is $1.04 / \mathrm{m}^{2}$ at least behind the working face. Therefore, as shown in Figure 13(b), in the upper entry retaining test of 43043 working face, each support row of lagging temporary support is designed as four single props, the row spacing is $0.5 \mathrm{~m}$ on the roof cutting side, and it is $1 \mathrm{~m}$ to other three rows. In addition, according to the monitoring of the gangue retaining pressure, the gangue wall tends to be stable when it is behind the working face more than $160 \mathrm{~m}$, so the lagging temporary support range is $0-160 \mathrm{~m}$ behind the working face at least.

\section{Simulation Analysis of Pressure Releasing}

Based on the above design, this section firstly uses numerical simulation software to simulate the stress distribution of surrounding rock under the condition of roof cutting and pressure releasing in the mining process and predicts and analyzes the effect of roof cutting from the theoretical point of view.

4.1. Model Establishment. In order to verify the design about the key technical parameters by numerical simulation, on the basis of considering actual engineering conditions and simplified calculation, the calculation model is established as $200 \mathrm{~m} \times 210 \mathrm{~m} \times 50 \mathrm{~m}$ by Flac $3 \mathrm{D}$ numerical simulation software. In this model, the entry excavation size is $200 \mathrm{~m} \times 4.6 \mathrm{~m} \times 3.6 \mathrm{~m}$, and the working face mining size is $100 \mathrm{~m} \times 170 \mathrm{~m} \times 3.6 \mathrm{~m}$. The calculation model is shown in Figure 15, which includes roof about $30 \mathrm{~m}$ thick, floor about $17 \mathrm{~m}$ thick, 1656800 grid units, and 1764670 nodes. The parameters of each rock layer are referenced in Table 2, and the roof cutting and no cutting conditions are simulated, respectively, to be compared $[28,29]$.

4.2. Simulation Analysis. The simulation results of section A-A are shown in Figure 16. Under the no roof cutting condition, there is an obvious stress concentration zone in the coal wall of entry, the maximum vertical stress is $57.8 \mathrm{MPa}$, and the stress concentration zone is closer to the entry wall (about $2.0 \mathrm{~m}$ ), which can easily lead to the adverse phenomenon of coal wall slice. Meanwhile, the entry roof is greatly influenced by the collapse of the goaf roof, whose subsidence is larger on the goaf side and smaller on the coal wall side, and the maximum subsidence is about $2500 \mathrm{~mm}$. However, under the roof cutting condition, the stress concentration range in the coal wall is smaller, the maximum vertical stress is $52.1 \mathrm{MPa}$, and the stress concentration zone is far from the entry wall (about $4.0 \mathrm{~m}$ ). Besides, the maximum vertical displacement of the entry roof is $1570 \mathrm{~mm}$, which is far less than the maximum value under no roof cutting condition. The above result shows that the roof cutting can effectively cut off the stress transfer between the 


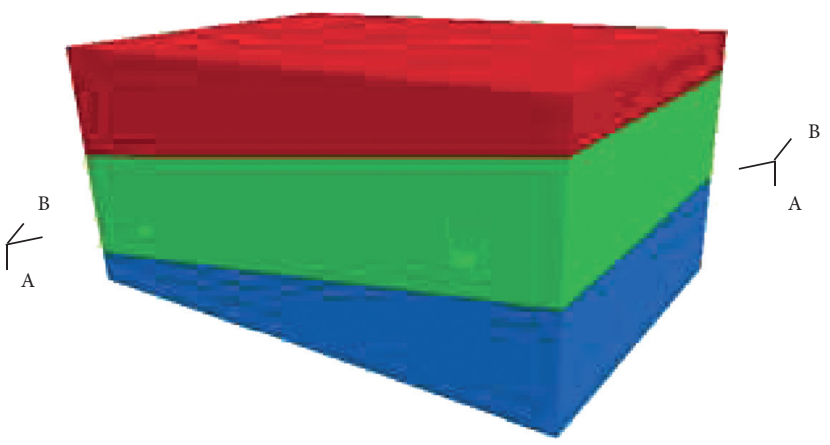

(a)

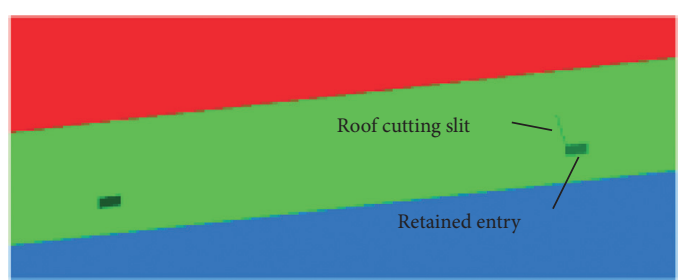

(b)

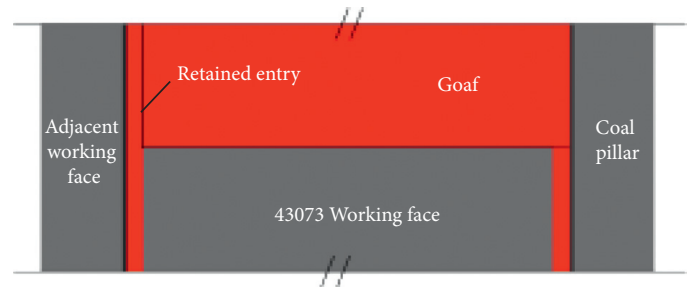

(c)

FIgURE 15: Numerical calculation model. (a) Three-dimensional model. (b) Section A-A. (c) Section B-B.

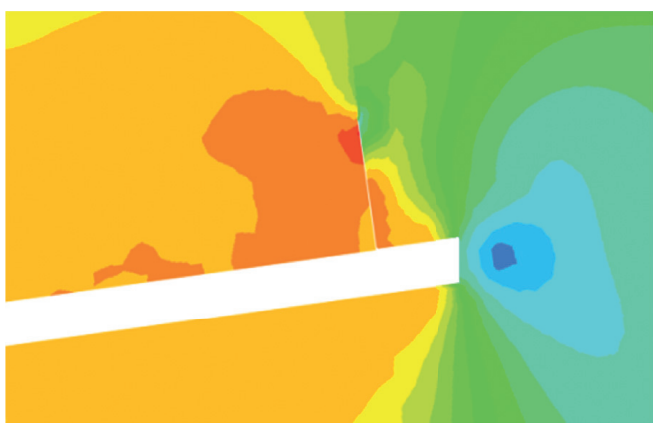

(1) Vertical stress distribution (Unit: Pa)

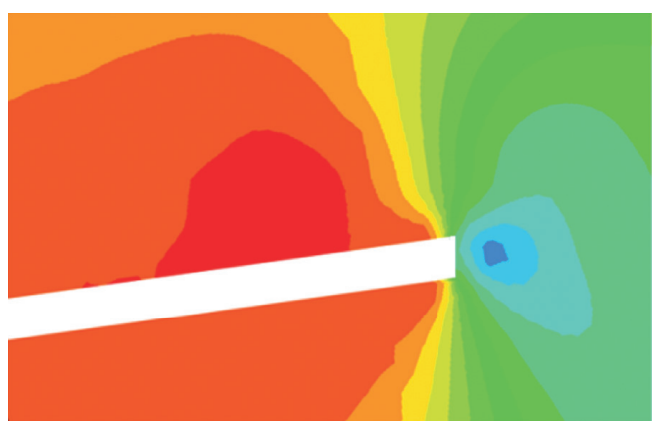

(1) Vertical stress distribution (Unit: $\mathrm{Pa}$ )

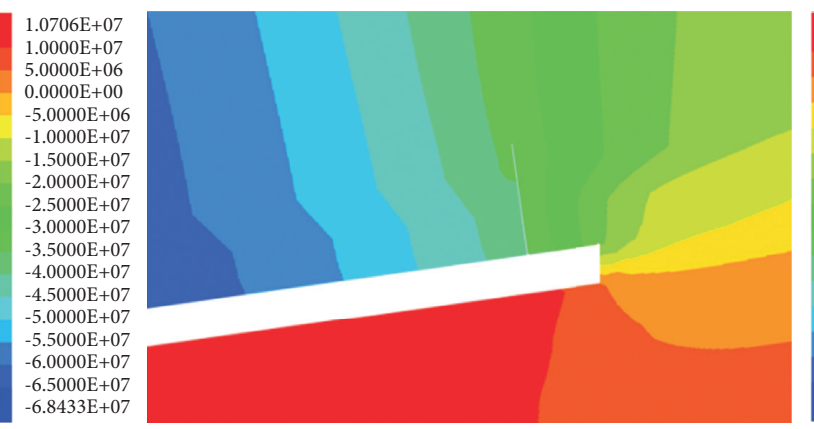

(2) Vertical displacement distribution (Unit: m)

(a)

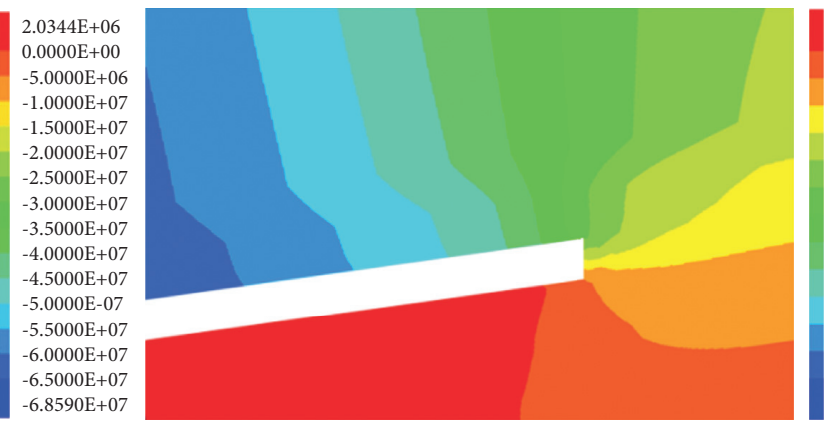

$2.9701 \mathrm{E}-03$ $0.0000 \mathrm{E}+00$

$-5.0000 \mathrm{E}-03$

$-1.0000 \mathrm{E}-02$

$-1.5000 \mathrm{E}-02$

$-2.0000 \mathrm{E}-02$

$-2.5000 \mathrm{E}-02$

$-3.0000 \mathrm{E}-02$

$-3.5000 \mathrm{E}-02$

$-4.0000 \mathrm{E}-02$

$-4.5000 \mathrm{E}-02$

$-5.0000 \mathrm{E}-02$

$-5.5000 \mathrm{E}-02$

$-6.0000 \mathrm{E}-02$

$-6.4005 \mathrm{E}-02$

(2) Vertical displacement distribution (Unit: m)

(b)

Figure 16: The simulation results of A-A section. (a) Simulation results of vertical stress and displacement under roof cutting. (b) Simulation results of vertical stress and displacement under no roof cutting.

entry roof and goaf roof, which can effectively control the deformation of retained entry roof.

In addition, the vertical stress distribution simulation result of the B-B section under roof cutting condition is shown in Figure 17. The distribution characteristics of the vertical stress field in the working face can be seen from the graph: (1) Vertical stress peak appears in front of the working face, and the peak stress value on the roof cutting side is less than that on the no cutting side. (2) Comparing the stress distribution of the coal seam at both sides of goaf, it 


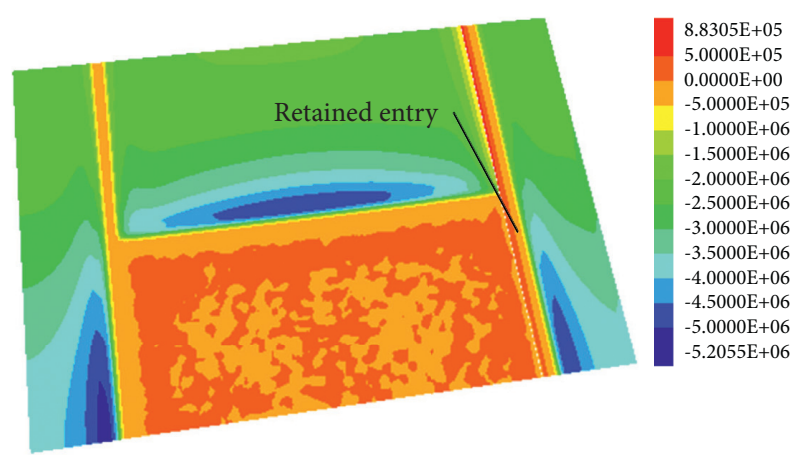

FIgURE 17: The vertical stress distribution simulation results of the B-B section (unit: Pa).

can be seen that the stress concentration range on the no roof cutting side is larger than that on the roof cutting side and the stress concentration value is also higher.

\section{Effect of Field Application}

Based on the above design and theoretical analysis, the characteristics of roof cutting effect under upper roadway have been analyzed systematically, which can effectively guide the field roof cutting test in the 43073 working face of Yixin coal mine. In the test process, the effect of entry retaining is evaluated by pressure monitoring of the working face and entry deformation monitoring. The relevant monitoring results and analysis are as follows.

5.1. Pressure Monitoring of Working Face. The 43073 working face is mined and its auxiliary entry is retained as the above design. There are 10 GPD60 W mine intrinsically safe wireless pressure sensors distributed in the working face to monitor the change of hydraulic support working resistance. The serial numbers of supports that installed sensors are $1,12,23,34,45,56,67,78,89$, and 100 . In order to analyze the effect of roof cutting pressure releasing, the working resistance monitoring data of hydraulic support near the no roof cutting side (1\# support), the middle of working face (45\# support), and the roof cutting side (100\# support) are chosen as Figures 18(a)-18(c) for comparison.

The statistical results of the weighting step and weighting strength about the above three typical supports are shown in Table 3. It can be seen that the weighting step is shortest and the weighting strength is highest in the middle of the working face. Affected by the roof cutting pressure releasing, the periodic weighting step on the entry retaining side is longer than that of the no roof cutting side, and the average increase is $3 \mathrm{~m}$. And the periodic weighting strength is lower on the roof cutting side, the decrease of average strength is 1.4 $\mathrm{MPa}$, and the decrease of peak strength is $6.8 \mathrm{MPa}$. The effect of roof cutting pressure releasing is obvious according to the above analysis.

Besides, according to the monitoring results of 10 marked hydraulic supports, the first weighting step, the periodic weighting step, the peak weighting strength, and the average weighting strength of the working face are statistically analyzed. The results are shown in Figure 19.

It can be seen that the weighting step and weighting strength distribution laws of the working face are consistent with the analysis results of the above three typical supports, and the weighting step and strength distributions are asymmetrical due to the influence of roof cutting at the entry retaining side. Compared to the no roof cutting side, the periodic weighting step is longer and weighting strength is weaker on the roof cutting side. The pressure releasing effect is obvious from the $78 \#$ hydraulic support, so the lateral influence range of roof cutting is approximately $37.4 \mathrm{~m}$ in the working face (the width of single hydraulic support is $1.7 \mathrm{~m}$ ), and the more close to the roof cutting line, the more significant the pressure releasing effect. What is more, affected by the roof cutting, on the entry retaining side of the working face, the peak weighting strength of hydraulic support is more affected than the average weighting strength. Specifically, compared to the no roof cutting side, the maximum releasing ratio of peak weighting strength is $17.5 \%$ and the maximum releasing ratio of average weighting strength is $4.1 \%$ on the roof cutting side of 43073 working face.

5.2. Entry Deformation Monitoring. As shown in Figure 20, the entry deformation monitoring uses the cross point method, and the length of line segment $\mathrm{AO}, \mathrm{OC}, \mathrm{BO}$, and OD should be measured every day at the monitoring section of entry. The entry deformation should be monitored from the monitoring section entering the advanced temporary support section until the deformation becomes stable. In the entry retaining and monitoring process, the deformation is the most severe at mining footage $130 \mathrm{~m}$ and the monitoring result of this section is shown in Figure 21.

According to the monitoring results above, the following can be seen: (1) The final deformation of retained entry floor heave is $143 \mathrm{~mm}$, the final deformation of roof subsidence is $218 \mathrm{~mm}$, and the final deformation of roof to floor convergence is $361 \mathrm{~mm}$. The change trends of roof subsidence and floor heave are the same basically, and the roof to floor convergence becomes stable when the retained entry is behind the working face more than $207 \mathrm{~m}$. (2) The final convergence deformation of the entry two sides is $280 \mathrm{~mm}$. The convergence is mainly manifested as the deformation of the coal wall in the early stage, and then with the gradually compacting of the gangue wall, the convergence is mainly manifested as the deformation of the gangue wall in the latter stage. The final lateral deformation of the gangue wall is $79 \mathrm{~mm}$, the final lateral deformation of coal wall is $201 \mathrm{~mm}$, and the convergence of two sides becomes stable when the retained entry is behind the working face more than $226 \mathrm{~m}$. In this section of retained entry, the final height on the roof cutting side is $1892 \mathrm{~mm}$ and the final width is $4320 \mathrm{~mm}$. The field effect of entry retaining is shown in Figure 22, and the retained entry is enough to meet the reuse demand of adjacent working face mining. 


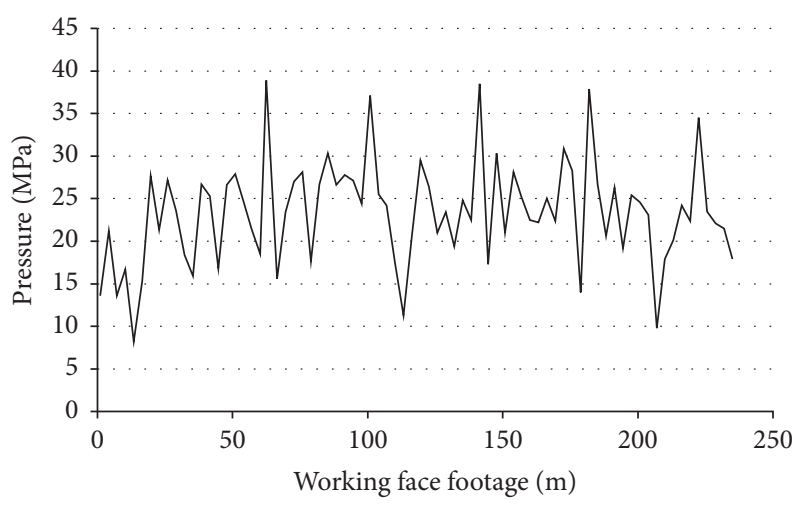

(a)

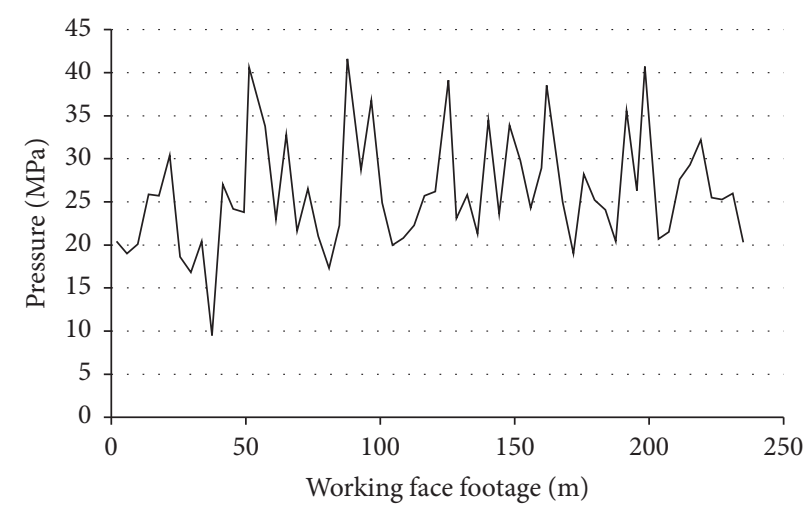

(b)

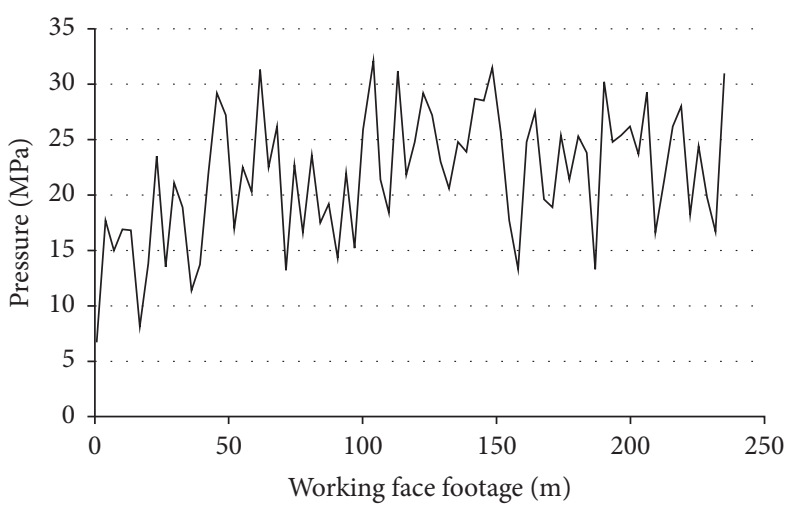

(c)

Figure 18: Monitoring diagram of typical hydraulic support. (a) 1\# support (near the no roof cutting side). (b) 45\# support (near the middle of the working face). (c) 100\# support (near the roof cutting side).

TABLE 3: Hydraulic support resistance statistic.

\begin{tabular}{lccccccc}
\hline \multirow{2}{*}{ Support number } & \multirow{2}{*}{ First weighting step (m) } & \multicolumn{3}{c}{ Periodic weighting step (m) } & Average pressure (MPa) & \multirow{2}{*}{ Peak pressure (MPa) } \\
& & 1 & 2 & 3 & Average & Ava \\
\hline 1 & 62 & 39 & 40 & 41 & 40 & 23.2 & 38.9 \\
45 & 51 & 37 & 37 & 38 & 37 & 26.1 & 41.6 \\
100 & 61 & 43 & 44 & 42 & 43 & 21.8 & 32.1 \\
\hline
\end{tabular}

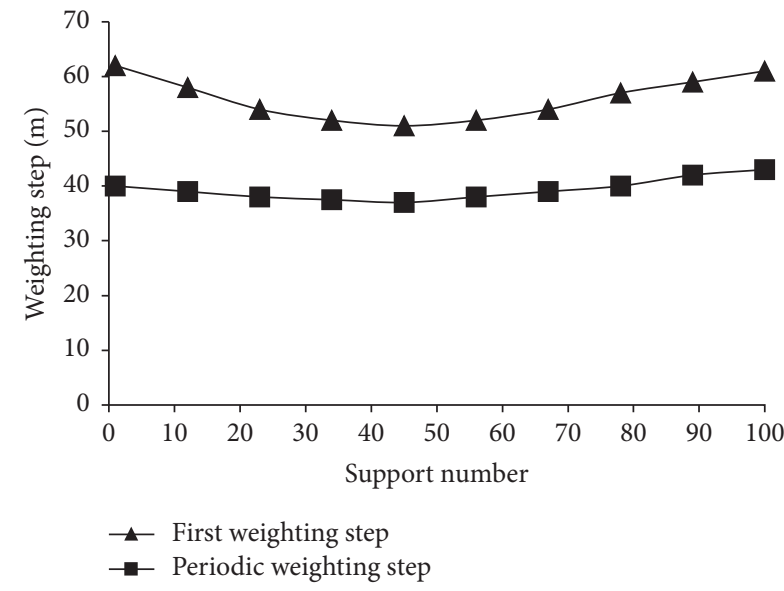

(a)

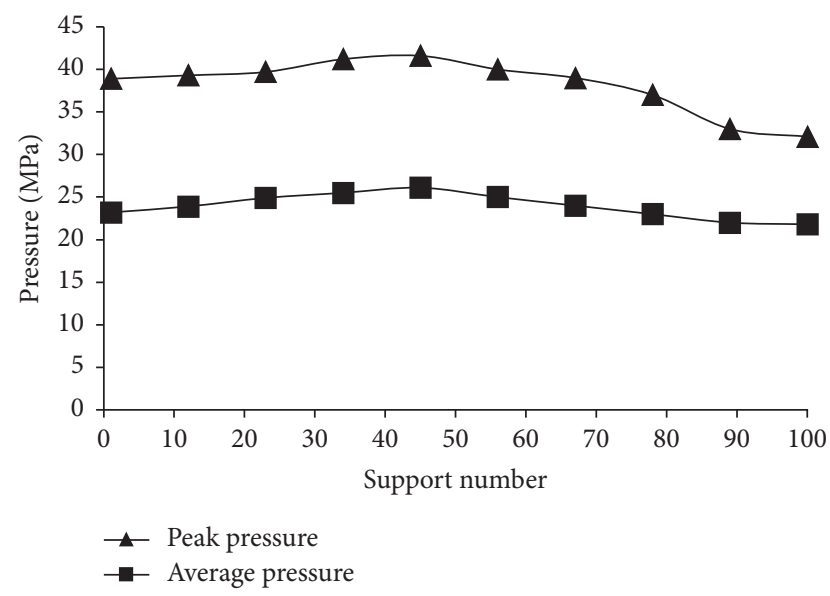

(b)

FIgURE 19: Pressure statistics of hydraulic support in working face. (a) Weighting step statist. (b) Weighting strength statistic. 


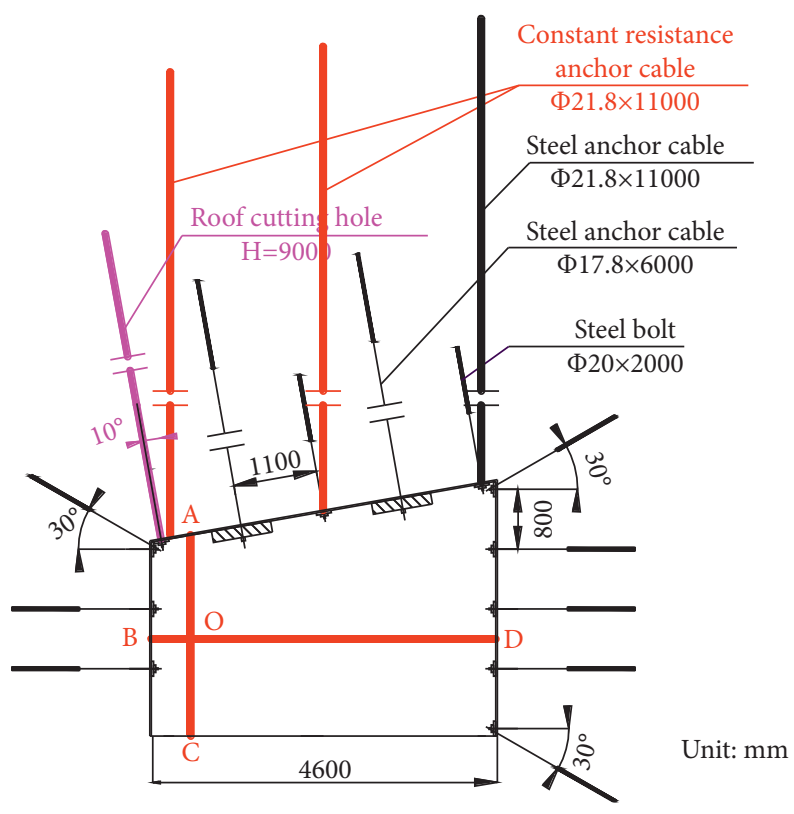

FIgURE 20: Monitoring design of roadway.

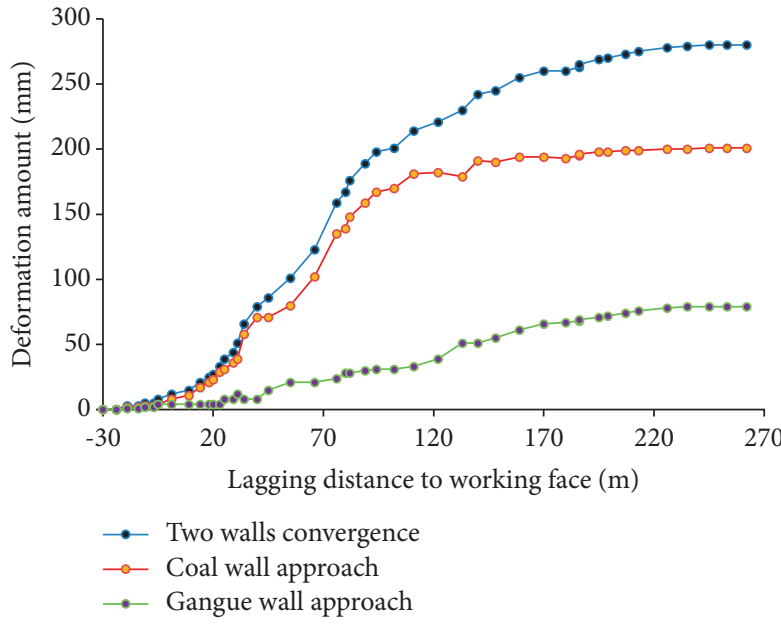

(a)

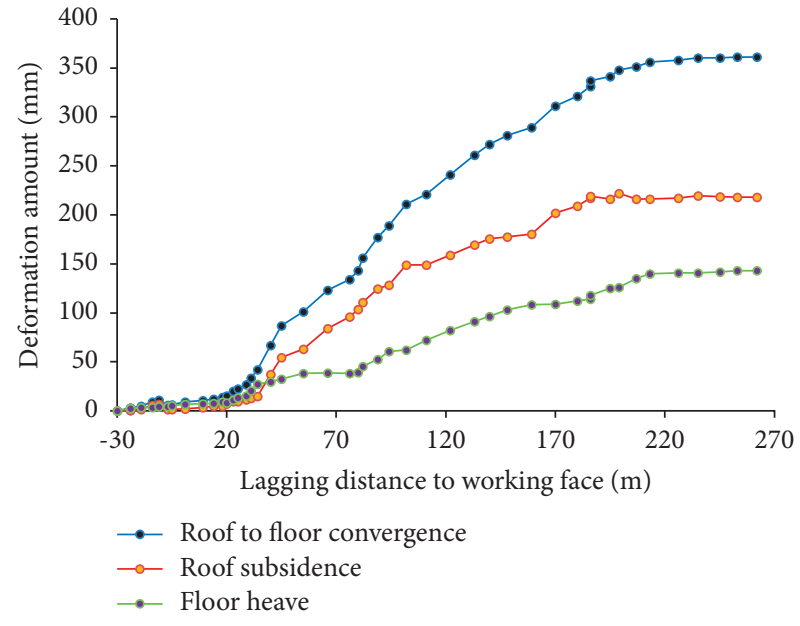

(b)

Figure 21: Monitoring results at $130 \mathrm{~m}$ footage section. (a) Two walls convergence. (b) Roof to floor convergence.

\section{Conclusions}

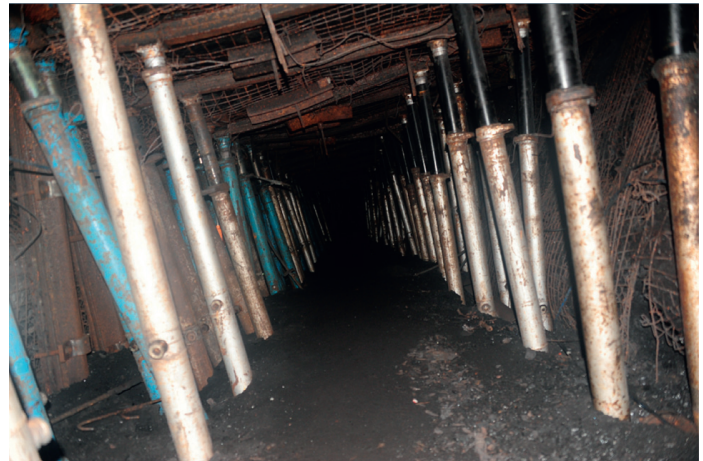

FIgURE 22: Field retaining effect.
(1) This paper analyzes the difficulties of upper entry retaining by roof cutting under inclined coal seam condition and puts forward the key technologies and system design to the special condition, which includes five parts: roof cutting, blasting, reinforcement support, gangue retaining support, and temporary support.

(2) Taking the 43073 working face of Yixin coal mine as an example, this paper makes the detail design of GERRC with upper entry under gently inclined thick coal seam condition, analyzes the roof cutting and pressure releasing effect by numerical simulation, and expounds the stress distribution and pressure 
releasing mechanism of surrounding rock under roof cutting.

(3) Entry retaining field test is carried out to verify the feasibility and applicability of the upper entry retaining design. Through the field monitoring, it is found that the weighting step increases significantly and the weighting strength decreases effectively on the roof cutting side; namely, the pressure releasing effect is obvious. Meanwhile, the maximum roof to floor convergence is $361 \mathrm{~mm}$ and the maximum shrinkage of both sides is $280 \mathrm{~mm}$, so the retained entry can meet the reuse requirement of adjacent working face.

\section{Data Availability}

All the data used to support the findings of this study are available from Xingen Ma upon request.

\section{Conflicts of Interest}

The authors declare that they have no conflicts of interest.

\section{Acknowledgments}

This research was financially supported by the State Key Laboratory for Geomechanics and Deep Underground Engineering (SKLGDUEK2020) and the Coal Burst Research Center of China Jiangsu.

\section{References}

[1] H. Kang, D. Niu, Z. Zhang, J. Lin, Z. Li, and M. Fan, “Deformation characteristics of supporting rock and supporting technology of gob-side entry retaining," Chinese Journal of Rock Mechanics and Engineering, vol. 29, no. 10, pp. 19771987, 2010.

[2] M. Mahoutian, M. Shekarchi, and N. A. Libre, "Application of steel fiber reinforced lightweight Aggregate concrete in Underground mining," Journal of Mining Science, vol. 47, no. 5, pp. 606-617, 2011.

[3] Q. Wang, Y. Wang, M. He et al., "Experimental research and application of automatically formed roadway without advance tunneling," Tunnelling and Underground Space Technology, vol. 114, Article ID 103999, 2021.

[4] J. Wang and G. Wang, "Discussion on gateway retained along goaf technology with roof breaking and pressure releasing," Coal engineering, vol. 1, pp. 24-26, 2012.

[5] H. Zhu, "Technology and application of reserving pier column method along goaf," Coal mine modernization, vol. 147, no. 6 , pp. 181-186, 2018.

[6] S. Zhang, Y. Liu, H. Liu, S. Jiang, Z. Liu, and H. Xu, "Optimal design of laneway's side support for gob-side entry retaining with solid cemented backfilling," Safety In Coal Mines, vol. 49, no. 3, pp. 48-51, 2018.

[7] Y. Li, "Supporting technology with filling beside roadways in gob-side entry retaining on fully-mechanized working face," Shanxi coal, vol. 49, no. 3, pp. 48-51, 2018.

[8] C. Zhu, M. C. He, X. H. Zhang, Z. G. Tao, Q. Yin, and L. F. Li, "Nonlinear mechanical model of constant resistance and large deformation bolt and influence parameters analysis of constant resistance behavior," Rock and Soil Mechanics, vol. 42, no. 7, pp. 1911-1924, 2021.

[9] M. He, X. Ma, F. Niu, J. Wang, and Y. Liu, "Adaptability research and application of rapid gob-side entry retaining formed by roof cutting and pressure releasing with composite roof and medium thick coal seam," Chinese Journal of Rock Mechanics and Engineering, vol. 37, no. 12, pp. 1-15, 2018.

[10] M. He, Z. Song, A. Wang, H. Yang, H. G. Qi, and G. Guo Zhi, "Theory of longwall mining by using roof cutting shortwall team and 110 method," Coal Science \& Technology Magazine, vol. 37, no. 1, pp. 1-9, 2017.

[11] X. Sun, X. Liu, G. Liang, and W. Wenda, "Key Parameters of gob-side entry retaining formed by roof cut and pressure releasing in thin coal seams," Chinese Journal of Rock Mechanics and Engineering, vol. 33, no. 7, pp. 1449-1456, 2014.

[12] G. Zhang, M. He, X. Yu, and Z. G. Huang, "Research on the technique of no-pillar mining with gob-side entry formed by advanced roof caving in the protective seam in Baijiao coal mine," Journal of Mining and Safety Engineering, vol. 28, no. 4, pp. 511-516, 2011.

[13] Q. Yin, J. Wu, C. Zhu, M. He, and Q. Meng, "Mechanical responses of sandstone exposed to high temperature under constant normal stiffness boundary conditions," Geomechanics and Geophysics for Geo-Energy and Geo-Resources, vol. 7, p. 35, 2021

[14] Z. Guo, J. Wang, T. Cao, and L. Y, "Research on key parameters of gob-side entry retaining automatically formed by roof cutting and pressure release in thin coal seam mining," Journal of China University of Mining and Technology, vol. 45, no. 9, pp. 879-885, 2016.

[15] X. Ma, M. He, and J. Sun, "Research on the design of roof Cutting parameters of non coal pillar bob-side entry retaining mining with roof cutting and pressure releasing," Geotechnical \& Geological Engineering, vol. 8, 2018.

[16] X. Ma, J. Wang, H. Wu, Y. Liu, and Q. Jiang, "Experimental study on blasting of roof cutting with no pillar mining in working face of Tashan Coal Mine," Coal Science and Technology, vol. 46, no. 6, pp. 27-32, 2018.

[17] C. Wang, M. He, and S. Wang, "Application of the bidirectional energy-cavity blasting technology in the jointed rock mass," Blasting, vol. 21, no. 2, pp. 39-42, 2004.

[18] X. Ma, M. He, J. Wang, and G. Yubing, "Mine strata pressure characteristics and mechanisms in gob-side entry retention by roof cutting under medium-thick coal seam and compound roof conditions," Energies, vol. 11, p. 2539, 2018.

[19] F. Gan, Y. Kang, X.-C. Wang, and H. Yaoqing, "Investigation on the failure characteristics and fracture classification of shale under Brazilian test conditions," Rock Mechanics and Rock Engineering, vol. 53, no. 7, pp. 3325-3340, 2020.

[20] C. Baosuo, K. Zhou, and M. He, "Optimization research on supporting parameters of roof cutting entry retaining with large mining height face," Coal Science and Technology, vol. 45 , no. 8, pp. 128-133, 2017.

[21] X. Ma, M. He, W. Li, and L. Lifeng, "Research and application of open-off cut roof cutting pressure releasing technology," Advances in Civil Engineering, vol. 2021, Article ID 9989213, 14 pages, 2021.

[22] M.-C. He, C. Li, W. Gong, J. Wang, and Z. Tao, "Support principles of NPR bolts/cables and control techniques of large deformation," Chinese Journal of Rock Mechanics and Engineering, vol. 35, no. 8, pp. 1513-1529, 2016.

[23] Y. Gao, M. He, J. Yang, and X. Ma, "Experimental study of caving and distribution laws of gangues influenced by roof fracturing in pillarless mining with gob-side entry retaining," 
Journal of China University of Mining and Technology, vol. 47, no. 1, pp. 116-127, 2018.

[24] F. Gan, X. Wang, M. Wang, and Y. Kang, "Experimental investigation of thermal cycling on fracture characteristics of granite in a geothermal-energy reservoir," Engineering Fracture Mechanics, vol. 235, Article ID 107180, 2020.

[25] Y. Gao, J. Yang, M. He, and S. Dingjie, "Mechanism and control techniques for gangue rib deformations in gob-side entry retaining formed by roof fracturing in thick coal seams," Chinese Journal of Rock Mechanics and Engineering, vol. 10, no. 36, pp. 2492-2502, 2017.

[26] X. Ma, Research on Key Technologies and Rock Pressure Law of 110 Mining Method with compound hard Roof in Tashan Coal Mine, China University of Mining and Technology, Beijing, China, 2019.

[27] M. He, S. Chen, and Z. Guo, "Control of surrounding rock structure for gob-side entry retaining by cutting roof to release pressure and its engineering application," Journal of China University of Mining and Technology, vol. 9, no. 46, pp. 959-969, 2017.

[28] G. Ramesh and R. Karpurapu, "Laboratory and numerical studies on the performance of geocell reinforced base layer overlying soft subgrade," International Journal of Geosynthetics and Ground Engineering, vol. 7, 2021.

[29] F. Wu, H. Zhang, Q. L. Zou, C. B. Li, J. Chen, and R. B. Gao, "Viscoelastic-plastic damage creep model for salt rock based on fractional derivative theory," Mechanics of Materials, vol. 150, Article ID 103600, 2020. 